\title{
Comparison of quality of life, satisfaction with surgery and shoulder-arm morbidity in breast cancer survivors submitted to breast-conserving therapy or mastectomy followed by immediate breast reconstruction
}

\author{
Renata Freitas-Silva, ${ }^{1}$ Délio Marques Conde, ${ }^{2}$ Ruffo de Freitas-Júnior, ${ }^{1}$ Edson Zangiacomi Martinez ${ }^{3}$ \\ 1 Department of Gynecology and Obstetrics, Universidade Federal de Goiás (UFG), Goiânia/GO, Brasil. 2 Breast Service, Hospital Materno Infantil (HMI),
} Goiânia/GO, Brasil. 3 Department of Social Medicine, Universidade de São Paulo (USP), Ribeirão Preto/SP, Brasil.

OBJECTIVES: This study was designed to compare the prevalence of shoulder-arm morbidity, patient satisfaction with surgery and the quality of life of women submitted to breast-conserving therapy or modified radical mastectomy and immediate breast reconstruction.

METHODS: This study was a cross-sectional study of women who underwent breast-conserving therapy $(n=44)$ or modified radical mastectomy and immediate breast reconstruction $(n=26)$. Quality of life was evaluated with the SF-36 Health Survey Questionnaire.

RESULTS: No differences were found in the prevalence of lymphedema. The movements that were most commonly affected by these procedures were abduction, flexion and external rotation. When the two groups were compared, however, we only found a statistically significant difference for the prevalence of restricted internal rotation, which occurred in $32 \%$ of women in the breast-conserving therapy group and $12 \%$ of those in the modified radical mastectomy and immediate breast reconstruction group (OR: 7.23; $p=0.03$ following adjustment for potential confounding factors). No difference in quality of life or satisfaction with surgery was found between the two groups.

CONCLUSIONS: These data suggest that the type of surgery did not affect the occurrence of lymphedema. Breastconserving therapy, however, increased the risk of shoulder movement limitation. No differences were found between the two surgical techniques with respect to quality of life or satisfaction with surgery.

KEYWORDS: Breast cancer; Quality of life; Lymphedema; Shoulder-arm morbidity, Aesthetic outcome.

Freitas-Silva R, Conde DM, Freitas-Júnior R, Martinez EZ. Comparison of quality of life, satisfaction with surgery and shoulder-arm morbidity in breast cancer survivors submitted to breast-conserving therapy or mastectomy followed by immediate breast reconstruction. Clinics. 2010;65(8):781-787.

Received for publication on March 8, 2010; First review completed on April 14, 2010; Accepted for publication on May 11, 2010

E-mail: condedelio@uol.com.br

Tel.: 5562 3209-6151

\section{INTRODUCTION}

Breast-conserving therapy (BCT) has become a safe option for the primary surgical treatment of early breast cancer. ${ }^{1}$ Nevertheless, there are cases where conservative treatment is impossible. In these cases, mastectomy followed by immediate reconstruction is one type of alternative treatment, and this procedure has yielded better aesthetic results. ${ }^{2}$ Another step in breast cancer surgery is the management of the axilla, which is done either by performing sentinel lymph node biopsy or complete axillary lymph node dissection. Breast-conserving therapy and

Copyright (c) 2010 CLINICS - This is an Open Access article distributed under the terms of the Creative Commons Attribution Non-Commercial License (http:// creativecommons.org/licenses/by-nc/3.0/) which permits unrestricted noncommercial use, distribution, and reproduction in any medium, provided the original work is properly cited. mastectomy may be associated with complications such as lymphedema ${ }^{3-7}$ and impaired shoulder function..$^{3,4,6,8}$

Previous studies associated shoulder-arm impairment, including lymphedema, with different techniques for breast cancer surgery. ${ }^{3,6,7}$ Risk factors reported for arm lymphedema include the number of affected lymph nodes, being overweight, the type of surgery ${ }^{7}$ and radiotherapy. ${ }^{9}$ Interestingly, some investigators have described a greater occurrence of lymphedema in women who underwent mastectomy. ${ }^{6-8,9,10}$ However, other studies have failed to identify the type of surgery as a risk factor for arm swelling., 3

In addition to lymphedema, previous studies have investigated shoulder-arm function and evaluated different movements such as flexion, abduction, extension and rotation. ${ }^{3,8,11}$ Studies have reported that women submitted to mastectomy were more likely to experience restricted range of motion (ROM) compared to women submitted to BCT. ${ }^{6,8}$ Nonetheless, other investigators failed to find any 
differences in arm mobility between different types of surgery. ${ }^{3,11}$ In addition to physical complications, breast cancer surgery may be associated with emotional repercussions, ${ }^{12}$ depression, ${ }^{13}$ difficulties at work and anxiety. ${ }^{14}$

Satisfaction with breast cancer surgery has also been investigated. Previous studies have shown that women submitted to BCT were more satisfied with the results of surgery than those submitted to mastectomy without reconstruction, $\mathrm{BCT}$ having been reported to be associated with a better body image $\mathrm{e}^{15-17}$ and greater satisfaction with cosmetic results. ${ }^{12,17}$ Other authors, however, have described higher levels of satisfaction in women submitted to mastectomy with reconstruction compared to women submitted to BCT. 2,18

Physical complications, emotional repercussions and satisfaction with the aesthetic results may affect the patient's perception of quality of life (QOL). Investigators have studied the association between the type of breast surgery and the patient's QOL; however, the results have been contradictory. ${ }^{2,3,16,19}$ Few studies have compared shoulderarm morbidity, satisfaction with surgery and the QOL of breast cancer survivors submitted to different forms of surgical therapy. The majority of the studies that have been published were conducted in developed countries, and conflicting data have been reported. Taking these factors into consideration and also considering the sociocultural factors that may affect a women's perception of QOL, the present study was designed to compare the prevalence of shoulder-arm morbidity, patient satisfaction with the primary surgical treatment and the QOL of breast cancer survivors submitted to BCT or modified radical mastectomy immediately followed by breast reconstruction (MRM+IBR).

\section{PATIENTS AND METHODS}

\section{Subjects}

A cross-sectional study was conducted at the Breast Cancer Outpatient Department of the Universidade Federal de Goiás, Goiânia Brazil between October 2007 and November 2008. This was a public healthcare service for women with breast cancer.

Patients in this study were recruited from a population of patients undergoing routine follow-up at the clinic. Breast cancer survivors were invited to participate in the study if they fulfilled all of the following criteria: patients who had been submitted to BCT or MRM+IBR with a transverse rectus abdominis myocutaneous (TRAM) flap, patients who had undergone complete axillary lymph node dissection and patients diagnosed at stages I, II or III who had completed oncological treatment at least six months prior to this study and were considered to be free of the disease. Women with bilateral breast cancer, women with a history of lymphedema of the arm, women who had been submitted to radiotherapy prior to breast cancer surgery and women with a history of other types of malignant neoplasia were excluded from the study. All patients underwent clinical staging according to the TMN classification system ( $\mathrm{T}$ describes the size of the tumor and whether it has invaded nearby tissue; $\mathrm{N}$ describes regional lymph nodes that are involved; $\mathrm{M}$ describes distant metastasis) and the staging system established by the American Joint Committee on Cancer in 1988.

Following outpatient consultation, 75 consecutive breast cancer patients were invited to participate in the study. Five patients refused to participate: two did not want to talk about the subject, and three claimed that they did not have time. Therefore, 70 breast cancer patients were included in the present study: 44 patients were in the BCT group, and 26 patients were in the MRM+IBR group.

Patients were interviewed for the purpose of collecting data on their sociodemographic and clinical characteristics, such as age, ethnicity, menopausal status, education level, marital status, smoking habits, employment status, monthly family income, body mass index (BMI) and current use of tamoxifen. Disease and treatment-related data were obtained from the patients' medical records, including age at the time of surgery, time since surgery, histological findings, number of lymph nodes removed, number of lymph nodes affected by the neoplasia, cancer stage, use of chemotherapy and radiotherapy. This study was approved by the Internal Review Board of the institution, and all women signed an informed consent form prior to enrollment.

\section{Quality of life assessment}

Quality of life was assessed with the Medical Outcomes Study 36-item Short-Form Health Survey (SF-36) questionnaire, ${ }^{20}$ a generic tool for evaluating QOL. The SF-36 had already been translated into Brazilian Portuguese and validated. $^{21}$ This instrument was previously used in other studies carried out in breast cancer survivors. ${ }^{19,22,23}$ It is a multidimensional questionnaire with eight components: physical functioning, physical role functioning, bodily pain, general health perceptions, vitality, social role functioning, emotional role functioning and mental health. These components may be grouped into two sets: the physical component summary (PCS) and the mental component summary (MCS). Each component is measured with a value ranging from 0 to 100 , with 0 and 100 corresponding to the poorest and optimal health statuses, respectively. ${ }^{24}$ The questionnaire was applied by one of the investigators in the form of an interview.

\section{Patient satisfaction with breast cancer surgery}

Patient satisfaction with the primary surgical treatment was investigated by posing seven additional questions that had already been used in a previous study ${ }^{12}$. The patients were asked the following questions, and they were told to respond to questions 2 through 6 using a 4-point scale (1 not at all; 2 - slightly; 3 - moderately; or 4 - very much so): 1) rate the aesthetic results of the operation using scores ranging from 1 (dreadful) to 7 (excellent); 2) was there a substantial change in physical appearance caused by the surgery; 3) did the patient's physical appearance cause her any emotional stress; 4) was everyday life still impaired as a result of the primary treatment; 5) did the patient regret her choice of surgical treatment; 6) to what extent did the patient fear a recurrence of the disease; and 7) whether a different choice of surgical treatment would have been made in hindsight (yes/no) (Table 1). ${ }^{12}$

\section{Evaluation of shoulder-arm morbidity}

Shoulder-arm morbidity was evaluated following breast surgery by investigating the prevalence of lymphedema and restrictions in the ROM of the arm. Lymphedema was evaluated by measuring the circumference of both arms. Using a tape measure, the circumference of the upper arms was measured at a point $15 \mathrm{~cm}$ above the olecranon, and the circumference of the forearms was measured at a point $10 \mathrm{~cm}$ below the olecranon. Lymphedema was diagnosed 
Table 1 - Questions used to investigate patient satisfaction with breast cancer surgery.

\begin{tabular}{|c|c|c|c|c|c|}
\hline Questions & \multicolumn{5}{|c|}{ Answers } \\
\hline 1. How would you evaluate the aesthetic results of your breast cancer surgery? & $\begin{array}{l}1 \text { dreadful } \\
\text { not at all }\end{array}$ & $2{ }^{3}$ & $\begin{array}{lc}4 & 5 \\
\text { moderately }\end{array}$ & $\begin{array}{l}6 \\
\text { very }\end{array}$ & $\begin{array}{l}7 \text { excellent } \\
\text { much so }\end{array}$ \\
\hline $\begin{array}{l}\text { 2. In your opinion, did breast cancer surgery result in a substantial change to your } \\
\text { physical appearance? }\end{array}$ & 1 & 2 & 3 & & 4 \\
\hline $\begin{array}{l}\text { 3. Has your physical appearance caused you any emotional stress in your } \\
\text { relationship with your partner, family or close friends? }\end{array}$ & 1 & 2 & 3 & & 4 \\
\hline 4. Is your everyday life still impaired as a result of the breast cancer surgery? & 1 & 2 & 3 & & 4 \\
\hline 5. Do you regret your choice of breast cancer surgery (BCT or $M R M+I B R)$ ? & 1 & 2 & 3 & & 4 \\
\hline 6. Do you fear a recurrence of breast cancer? & 1 & 2 & 3 & & 4 \\
\hline 7. In hindsight, would you opt for a different surgical treatment of breast cancer? & Yes & - & - & & No \\
\hline
\end{tabular}

when a difference $\geq 2 \mathrm{~cm}$ was found between the circumference of the ipsilateral arm and the contralateral arm at one of the measuring points. ${ }^{4,8}$ This criterion is commonly used in the current literature. ${ }^{25}$ Following identification, the lymphedema was then classified as mild $(<3 \mathrm{~cm})$, moderate $(3-5 \mathrm{~cm})$ or severe $(>5 \mathrm{~cm}){ }^{26}$

To evaluate arm mobility, ROM was measured on both sides using a goniometer. Comparing goniometric measurements of the affected and unaffected arms, a difference $\geq 10^{\circ}$ was considered to constitute restricted mobility or impaired shoulder function. ${ }^{3}$ The following shoulder movements were evaluated: abduction, flexion, extension, internal rotation and external rotation.

\section{Statistical analysis}

The distribution of the sociodemographic and clinical characteristics of the breast cancer survivors, expressed as qualitative variables, was compared between the groups submitted to MRM+IBR and BCT using Fisher's exact test. The means of the population characteristics, expressed as continuous variables, were compared using Student's t-tests for independent samples. The associations with lymphedema and restricted ROM were measured using odds ratios (OR) with the respective $95 \%$ confidence intervals $(95 \% \mathrm{CI})$, which were obtained by unconditional logistic regression analysis $^{27}$ with adjustments for potential confounding variables. The median scores for satisfaction with the surgery and QOL were compared between groups using least absolute value regression ${ }^{28}$ with adjustments for potential confounding variables. A significance level of 0.05 was adopted for all of the tests.

\section{RESULTS}

The mean ages of the patients in this study were $47.6 \pm 7.4$ years old for the women submitted to MRM+IBR and $50.2 \pm 7.3$ years old for the women submitted to BCT $(p=0.16)$. Eighty-five percent of the women submitted to MRM+IBR and $93 \%$ of those submitted to BCT were postmenopausal $(p=0.41)$. The mean monthly family income in U.S. dollars was $\$ 430.45 \pm 241.75$ and $\$ 490.31 \pm 432.22$ for women submitted to MRM+IBR and $\mathrm{BCT}$, respectively $(\mathrm{p}=0.49)$ (Table 2$)$.

The mean ages at surgery were $45.0 \pm 7.4$ years old for the women submitted to MRM+IBR and $46.9 \pm 7.0$ years old for women submitted to BCT $(\mathrm{p}=0.29)$. In the group of women submitted to MRM+IBR, $15 \%$ of the cases were classified as stage III, whereas $5 \%$ of the cases in the BCT group were classified as stage III $(p=0.02)$. All of the women in the BCT group and $38 \%$ of the women in the MRM+IBR group were submitted to radiotherapy $(\mathrm{p}<0.01)$. There was no difference between the two groups with respect to other disease characteristics or treatment-related features (Table 3).

The prevalence of lymphedema in the total population of the study was $15.7 \%$, whereas it was $12 \%$ in the MRM+IBR group and $18 \%$ in the BCT group (OR: $0.51 ; p=0.66$ ). All of the cases of lymphedema in our patients were mild. The most commonly affected movements were abduction, flexion and external rotation; however, we only observed a statistically significant difference between the two groups for restricted internal rotation $32 \%$ in the BCT group vs. $12 \%$ in the MRM+IBR group; OR: $7.23, \mathrm{p}=0.03$ following adjustment for potential confounding factors) (Table 4).

Table 2 - Sociodemographic and clinical features of women with breast cancer submitted to $\operatorname{MRM}+\operatorname{IBR}(n=26)$ or BCT $(n=44)$.

\begin{tabular}{|c|c|c|c|}
\hline Characteristic & MRM+IBR & BCT & p-value \\
\hline Age (years)* & $47.6(7.4)$ & $50.2(7.3)$ & $0.16^{1}$ \\
\hline $\begin{array}{l}\text { Education level (years of } \\
\text { schooling)* }\end{array}$ & $7.6(3.3)$ & $6.3(3.5)$ & $0.14^{1}$ \\
\hline Race/ethnicity \# & & & $0.28^{2}$ \\
\hline White & $7(27)$ & $15(34)$ & \\
\hline Other & $19(73)$ & $29(66)$ & \\
\hline Marital status $\#$ & & & $0.83^{2}$ \\
\hline Single & 5 (19) & $8(18)$ & \\
\hline Married & $10(38)$ & $21(48)$ & \\
\hline Cohabiting & $4(15)$ & $7(16)$ & \\
\hline Separated/divorced & $3(12)$ & $2(5)$ & \\
\hline Smoker \# & & & $0.53^{2}$ \\
\hline yes & $0(0)$ & $2(5)$ & \\
\hline no & $26(100)$ & $42(95)$ & \\
\hline Monthly family income (\$US)* & $430.45(241.75)$ & $490.31(432.22)$ & $0.49^{1}$ \\
\hline Employment status \# & & & $1.00^{2}$ \\
\hline In paid employment & $7(27)$ & $11(25)$ & \\
\hline Housewife & $16(62)$ & $28(64)$ & \\
\hline Retired & $3(12)$ & $5(11)$ & \\
\hline Body index mass $\left(\mathrm{kg} / \mathrm{m}^{2}\right)^{\#}$ & & & $0.17^{2}$ \\
\hline$<25$ & $12(48)$ & $13(30)$ & \\
\hline $25-30$ & $10(40)$ & $18(41)$ & \\
\hline$\geq 30$ & $3(12)$ & $13(30)$ & \\
\hline Menopausal status $\#$ & & & $0.41^{2}$ \\
\hline Premenopausal & $4(15)$ & $3(7)$ & \\
\hline Postmenopausal & $22(85)$ & $41(93)$ & \\
\hline
\end{tabular}

*Values expressed as means ( \pm SD)

\#Values expressed as N (\%)

${ }^{1}$ Student's $t$ test

${ }^{2}$ Fisher's exact test 
Table 3 - Disease and treatment-related features of women with breast cancer submitted to MRM+IBR $(n=26)$ or BCT $(n=44)$.

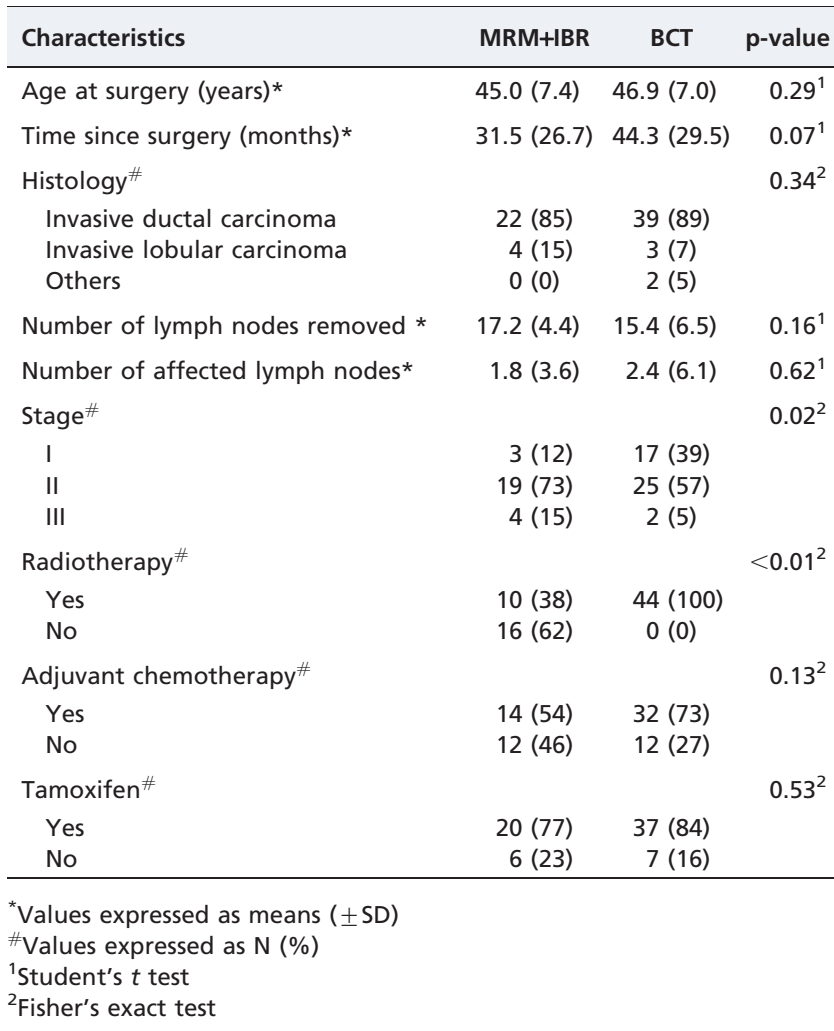

When the patients were asked whether they would have opted for a different surgical technique, $25 \%$ in the MRM+IBR group and $12 \%$ in the BCT group stated that they would have made a different choice (adjusted analysis, OR: $7.4 ; 95 \% C I$ : $0.7-73.3 ; p=0.09)$. No differences in the other items regarding satisfaction with surgery were found between the two groups in the adjusted or non-adjusted analyses (Table 5).

The highest QOL scores were found in the emotional role functioning domain for women in both the BCT and MRM+IBR groups (the median was 100 for both groups). The lowest scores were in the physical role functioning domain with medians of 0 and 25 for the MRM+IBR and BCT groups, respectively. No differences were found in the median QOL scores in the non-adjusted analyses or in the analyses adjusted for potential confounding factors (Table 6).

\section{DISCUSSION}

This cross-sectional study compared shoulder-arm morbidity, patient satisfaction with the primary surgical treatment and the QOL of breast cancer survivors submitted to MRM+IBR or BCT. Previous studies that investigated these parameters reported conflicting results, and the majority of these studies were conducted in developed countries. $3,5,12,17,19,29$ The present study reports findings in a cohort of Brazilian breast cancer survivors.

One study suggested that the frequency of lymphedema in breast cancer survivors varied between 0 and $56 \% .{ }^{30}$ In the present study, the prevalence of arm edema in the overall study population was $15.7 \%$, and there was no
Table 4 - Prevalence of lymphedema and restriction of shoulder movement in breast cancer survivors submitted to MRM+IBR $(n=26)$ or BCT $(n=44)$.

\begin{tabular}{|c|c|c|c|c|}
\hline Variables & Group & n (\%) & $\begin{array}{l}\text { Adjusted OR } \\
\qquad(95 \% \mathrm{Cl})\end{array}$ & $\begin{array}{c}\text { Adjusted } \\
\text { p-value }^{a}\end{array}$ \\
\hline \multirow[t]{2}{*}{ Lymphedema } & MRM+IBR & $3(12)$ & $0.51(0.02-10.1)$ & 0.66 \\
\hline & $\mathrm{BCT}$ & $8(18)$ & & \\
\hline \multirow[t]{2}{*}{ Abduction } & MRM+IBR & $18(69)$ & $0.17(0.08-3.37)$ & 0.25 \\
\hline & $\mathrm{BCT}$ & $24(55)$ & & \\
\hline \multirow[t]{2}{*}{ Flexion } & MRM+IBR & $17(65)$ & $0.50(0.02-9.91)$ & 0.65 \\
\hline & $\mathrm{BCT}$ & $33(35)$ & & \\
\hline \multirow[t]{2}{*}{ Extension } & MRM+IBR & $1(4)$ & $3.88(0.05-291)$ & 0.12 \\
\hline & $\mathrm{BCT}$ & $9(30)$ & & \\
\hline \multirow[t]{2}{*}{ Internal rotation } & MRM+IBR & $3(12)$ & $7.23(1.28-17.1)$ & 0.03 \\
\hline & $\mathrm{BCT}$ & $14(32)$ & & \\
\hline \multirow[t]{2}{*}{ External rotation } & MRM+IBR & $15(58)$ & $0.20(0.03-1.70)$ & 0.14 \\
\hline & $\mathrm{BCT}$ & $16(36)$ & & \\
\hline
\end{tabular}

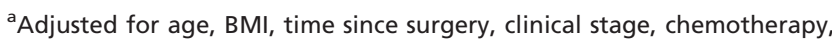
radiotherapy, number of lymph nodes removed, presence of affected lymph nodes and current use of tamoxifen, using unconditional logistic regression models.

difference in frequency between the group of women submitted to MRM+IBR and the group submitted to BCT. Some investigators failed to identify any association between the type of surgery and lymphedema; ${ }^{3,11}$ however, other authors reported a correlation. ${ }^{6-10}$ Kuehn et al. ${ }^{3}$ used a difference in volume of $\geq 10 \%$ between arms as a diagnostic criterion and reported lymphedema in $22.7 \%$ of women submitted to mastectomy or BCT. In agreement with the present results, these authors did not find an association between the type of surgery and arm edema. A prospective observational study ${ }^{10}$, however, showed that mastectomy was more likely to be associated with lymphedema than wide local excision and lumpectomy. In a case-control study, the investigators performed a univariate analysis and identified mastectomy as a risk factor for lymphedema; however, the association between mastectomy and lymphedema disappeared after multivariate analysis. ${ }^{7}$ The same study found that reconstructive surgery was not associated with the occurrence of lymphedema. Nesvold et al. ${ }^{6}$ investigated breast cancer survivors at a median of 47 months following surgery and described an association between mastectomy and arm edema. In addition, a recent meta-analysis found an association between mastectomy and lymphedema. ${ }^{9}$ The differences between the results of these studies may be related to the different criteria for lymphedema and the time between breast cancer surgery and analysis.

Another possible complication of breast cancer surgery is reduced ROM. Only a few studies have compared the prevalence of this complication across different types of surgery, and they have reported conflicting results. Some investigators failed to find any difference in the prevalence of restricted ROM between women submitted to mastectomy and those submitted to BCT.,11 Other authors, however, have described a greater occurrence of impaired shoulder-arm function in mastectomized women. ${ }^{5,6,8}$ In this case study, restriction of internal rotation was more common in the BCT group. Interestingly, a recent crosssectional study ${ }^{6}$ found that MRM was associated with a greater risk of limitation of shoulder abduction and flexion, which confirmed the findings of other investigators. ${ }^{5,8}$ In 
Table 5 - Comparison between the median scores of patient satisfaction with surgery in women with breast cancer submitted to MRM+IBR $(n=26)$ or BCT $(n=44)$.

\begin{tabular}{|c|c|c|c|c|c|}
\hline Variables & Group & Median & $\begin{array}{c}\text { Percentiles } \\
25-75 \%\end{array}$ & $\begin{array}{c}\text { Crude } \\
\text { p-value }\end{array}$ & $\begin{array}{l}\text { Adjusted } \\
\text { p-value* }\end{array}$ \\
\hline Aesthetic outcome & $\begin{array}{l}\text { MRM+IBR } \\
\text { BCT }\end{array}$ & $\begin{array}{l}66.7 \\
75.0\end{array}$ & $\begin{array}{l}66.7-83.3 \\
50.0-83.3\end{array}$ & 1.0 & 0.88 \\
\hline Change in physical appearance & $\begin{array}{l}\text { MRM+IBR } \\
\text { BCT }\end{array}$ & $\begin{array}{l}33.3 \\
33.3\end{array}$ & $\begin{array}{l}0-66.7 \\
0-66.7\end{array}$ & 1.0 & 0.95 \\
\hline Disturbed by appearance & $\begin{array}{l}\text { MRM+IBR } \\
\text { BCT }\end{array}$ & $\begin{array}{l}0 \\
0\end{array}$ & $\begin{array}{l}0-0 \\
0-33.3\end{array}$ & 1.0 & 1.0 \\
\hline Impairment to daily life & $\begin{array}{l}\text { MRM+IBR } \\
\text { BCT }\end{array}$ & $\begin{array}{l}33.3 \\
33.3\end{array}$ & $\begin{array}{l}0-66.7 \\
0-66.7\end{array}$ & 1.0 & 0.50 \\
\hline Regret & $\begin{array}{l}\text { MRM+IBR } \\
\text { BCT }\end{array}$ & $\begin{array}{l}0 \\
0\end{array}$ & $\begin{array}{l}0-0 \\
0-0\end{array}$ & 1.0 & 1.0 \\
\hline Fear of recurrence & $\begin{array}{l}\text { MRM+IBR } \\
\text { BCT }\end{array}$ & $\begin{array}{l}66.7 \\
66.7\end{array}$ & $\begin{array}{l}33.3-100 \\
33.3-100\end{array}$ & 1.0 & 0.70 \\
\hline
\end{tabular}

${ }^{*}$ Comparison between medians using least absolute value regression with adjustment for age, BMI, time since surgery, clinical stage, chemotherapy, radiotherapy, lymphedema, number of removed lymph nodes, presence of affected lymph nodes and current use of tamoxifen.

another study ${ }^{5}$ involving breast cancer survivors with a mean age of 59 years, limitation of shoulder abduction was found to be more common in mastectomized women than women in receiving BCT. When comparing the findings from the different studies, certain aspects must be taken into consideration. These studies differ with respect to design, the definition of reduced movement and surgical techniques. Kuehn et al. ${ }^{3}$ used a difference of $\geq 10^{\circ}$ as a cut-off value to define reduced ROM, whereas Nesvold et al. ${ }^{6}$ used a difference of $\geq 25^{\circ}$, and Ernst et al. ${ }^{11}$ and Voogd et al..$^{5}$ used a difference of $\geq 20^{\circ}$. These studies included women submitted to either BCT or MRM. It is important to note that the present study included women submitted to BCT or MRM+IBR. Therefore, we suggest that future prospective studies with larger sample sizes should be carried out to investigate impaired shoulder-arm function in women submitted to mastectomy with reconstruction.

According to the literature, the association between the type of surgery, body image and satisfaction is controversial. The two surgical techniques investigated in the present study were used with the objective of achieving oncological safety and good aesthetic results. Although tumor-related aspects must be taken into consideration, the participation of the woman is fundamental in selecting the type of

Table 6 - Comparison between the median SF-36 scores for women with breast cancer submitted to MRM+IBR $(n=26)$ or BCT $(n=44)$.

\begin{tabular}{|c|c|c|c|c|c|}
\hline SF-36 domains & Group & Median & $\begin{array}{r}\text { Percentiles } \\
25-75 \%\end{array}$ & $\begin{array}{c}\text { Crude } \\
\text { p-value }\end{array}$ & $\begin{array}{l}\text { Adjusted } \\
\text { p-value* }\end{array}$ \\
\hline Physical functioning & $\begin{array}{l}\text { MRM+IBR } \\
\text { BCT }\end{array}$ & $\begin{array}{l}72.5 \\
62.5\end{array}$ & $\begin{array}{l}65.0-85.0 \\
40.0-80.0\end{array}$ & 0.23 & 0.16 \\
\hline Physical role functioning & $\begin{array}{l}\text { MRM+IBR } \\
\text { BCT }\end{array}$ & $\begin{array}{c}0 \\
25.0\end{array}$ & $\begin{array}{l}0-50.0 \\
0-75.0\end{array}$ & 0.28 & 0.55 \\
\hline Emotional role functioning & $\begin{array}{l}\text { MRM+IBR } \\
\text { BCT }\end{array}$ & $\begin{array}{l}100 \\
100\end{array}$ & $\begin{array}{r}33.3-100 \\
0-100\end{array}$ & 1.0 & 0.44 \\
\hline Bodily pain & $\begin{array}{l}\text { MRM+IBR } \\
\text { BCT }\end{array}$ & $\begin{array}{l}51.0 \\
51.5\end{array}$ & $\begin{array}{l}30.0-64.5 \\
34.2-72.0\end{array}$ & 0.87 & 0.48 \\
\hline Vitality & $\begin{array}{l}\text { MRM+IBR } \\
\text { BCT }\end{array}$ & $\begin{array}{l}72.5 \\
67.5\end{array}$ & $\begin{array}{l}50.0-90.0 \\
51.2-78.8\end{array}$ & 0.38 & 0.56 \\
\hline Mental health & $\begin{array}{l}\text { MRM+IBR } \\
\text { BCT }\end{array}$ & $\begin{array}{l}72.0 \\
74.0\end{array}$ & $\begin{array}{l}52.0-81.0 \\
57.0-84.0\end{array}$ & 1.0 & 0.95 \\
\hline Social role functioning & $\begin{array}{l}\text { MRM+IBR } \\
\text { BCT }\end{array}$ & $\begin{array}{c}100 \\
87.5\end{array}$ & $\begin{array}{l}59.3-100 \\
37.5-100\end{array}$ & 0.47 & 0.94 \\
\hline General health perceptions & $\begin{array}{l}\text { MRM+IBR } \\
\text { BCT }\end{array}$ & $\begin{array}{l}63.5 \\
60.0\end{array}$ & $\begin{array}{l}60.0-72.7 \\
45.5-77.0\end{array}$ & 0.37 & 0.95 \\
\hline Physical component summary & $\begin{array}{l}\text { MRM+IBR } \\
\text { BCT }\end{array}$ & $\begin{array}{l}40.7 \\
41.4\end{array}$ & $\begin{array}{l}34.1-49.4 \\
34.0-48.1\end{array}$ & 0.88 & 0.76 \\
\hline Mental component summary & $\begin{array}{l}\text { MRM+IBR } \\
\mathrm{BCT}\end{array}$ & $\begin{array}{l}51.2 \\
51.1\end{array}$ & $\begin{array}{l}45.2-58.1 \\
38.3-59.2\end{array}$ & 0.99 & 0.58 \\
\hline
\end{tabular}

${ }^{*}$ Comparison between medians using least absolute value regression with adjustment for age, BMI, duration of surgery, clinical stage, chemotherapy, radiotherapy, lymphedema, number of removed lymph nodes, presence of affected lymph nodes and current use of tamoxifen. 
surgery because sociocultural factors may affect the choice. Some studies have shown better aesthetic results with conservative surgery ${ }^{2,31}$, whereas other studies found that breast reconstruction resulted in a better outcome. ${ }^{32}$ Nicholson et al. ${ }^{32}$ compared women submitted to reconstructive surgery, conservative surgery or simple mastectomy and reported a better aesthetic outcome with reconstructive surgery (compared with conservative surgery) and better results with conservative surgery compared to simple mastectomy. The patients of the present study declared themselves satisfied with the aesthetic results of their surgery, and no difference was found between the groups in this respect. ${ }^{18}$

Using the same questionnaire that was applied in the present study, Janni et al. ${ }^{12}$ showed that German women submitted to mastectomy were less satisfied with the aesthetic results of their surgery than women submitted to BCT. These authors also reported that mastectomized women had a greater dislike of their physical appearance and more emotional stress resulting from the surgery. ${ }^{12}$ In addition, a greater proportion of these women reported that they would have opted for a different type of surgery if they could choose again. These differences were not found in the women of the present cohort. Although conservative treatment was associated with a greater risk of disease recurrence, ${ }^{1}$ no difference was found between the groups with respect to the fear of a recurrence. Interestingly, some studies ${ }^{17,33}$ have described a greater fear of recurrence in women submitted to BCT, but other studies could not confirm this difference ${ }^{34,35}$, even when the women were aware of the higher risk of recurrence with conservative surgery. ${ }^{1}$ Fear of recurrence and satisfaction with aesthetic results are factors that may affect psychological adjustment and the woman's perception of her QOL. ${ }^{32}$

In the current study, no difference was found between the two surgical groups with respect to QOL. Findings from some previous studies are in agreement with the present results. 2,12,15,36 Other studies, however, have identified differences in QOL in breast cancer survivors as a function of the type of surgical procedure. ${ }^{16,19,22,23,37}$ Dian et al. ${ }^{19}$ investigated QOL using the SF-36 questionnaire and reported better scores in physical functioning in women submitted to breast reconstruction compared with those submitted to conservative surgery. Other investigators have reported poor physical functioning in women undergoing BCT compared with those submitted to mastectomy. ${ }^{22,37}$

Recently, Parker et al. ${ }^{23}$ conducted a prospective study comparing the QOL of women submitted to mastectomy with reconstruction to that of women submitted to mastectomy without reconstruction or women submitted to breast conservation. One month after surgery, these authors showed a reduction in PCS and MCS scores in all three groups. There were no differences between the groups with respect to QOL during long-term follow-up. These results are in agreement with the findings of the present study, which did not find any differences in the PCS or MCS scores of women submitted to MRM+IBR or breast conservation. In the present study, better scores were found in the emotional role-functioning and social rolefunctioning domains, which suggests that conditions were favorable for these women in these domains. Despite the possible negative repercussions of diagnosis and treatment, these components of QOL were not severely affected. The lowest scores were found for the physical role functioning domain; however, there were no differences between the two surgical groups. This finding indicates that breast cancer survivors experienced physical limitations in performing their daily activities regardless of the type of surgery.

The differences between the various studies that have investigated associations between the type of surgery and the QOL of breast cancer survivors may be related to several aspects, particularly the type of questionnaire used (specific versus generic), sociocultural characteristics and the time between surgery and evaluation because QOL tends to return to pre-surgical levels over time. ${ }^{23}$

There are some limitations in the interpretation of the findings of the present study. Because this was a crosssectional study, it was not possible to establish causal inferences. Another possible limitation is posed by the absence of a group of women submitted to mastectomy without reconstruction, which may have introduced new findings. In addition, the relatively small sample size was a limitation.

The fact that the QOL questionnaire used in this study has been validated internationally and used in various studies involving breast cancer survivors constitutes one of the strengths of the present study. Moreover, in addition to QOL, this study also investigated specific aspects related to breast cancer surgery, such as lymphedema, reduced ROM and satisfaction with aesthetic outcome.

In conclusion, these findings offer interesting data for professionals involved in the care of breast cancer survivors. The results show that BCT and MRM+IBR score similarly with respect to QOL and satisfaction with surgery. Moreover, they show that shoulder-arm morbidity and the frequency of lymphedema were similar in both surgical groups, and the risk of a restriction in ROM was greater in Brazilian breast cancer survivors submitted to BCT.

Future prospective studies should be carried out in women submitted to mastectomy with or without reconstruction to permit comparison of different techniques of breast reconstruction, including TRAM flap and breast implant reconstruction. These studies should utilize generic and specific QOL questionnaires that would permit upper limb symptoms to be investigated. ${ }^{38}$ Because not all surgery-related aspects are covered in the currently available QOL instruments, future studies should investigate the physical and emotional repercussions associated with surgery using a questionnaire specifically constructed for this purpose.

\section{REFERENCES}

1. Veronesi U, Cascinelli N, Mariani L, Greco M, Saccozzi R, Luini A, et al. Twenty-year follow-up of a randomized study comparing breastconserving surgery with radical mastectomy for early breast cancer. N Engl J Med. 2002;347:1227-32, doi: 10.1056/NEJMoa020989.

2. Cocquyt VF, Blondeel PN, Depypere HT, Van De Sijpe KA, Daems KK, Monstrey SJ, et al. Better cosmetic results and comparable quality of life after skin-sparing mastectomy and immediate autologous breast reconstruction compared to breast conservative treatment. $\mathrm{Br}$ Plast Surg. 2003;56:462-70, doi: 10.1016/S0007-1226(03)00198-X.

3. Kuehn T, Klauss W, Darsow M, Regele S, Flock F, Maiterth C, et al. Longterm morbidity following axillary dissection in breast cancer patients clinical assessment, significance for life quality and the impact of demographic, oncologic and therapeutic factors. Breast Cancer Res Treat. 2000;64:275-86, doi: 10.1023/A:1026564723698.

4. Nagel PH, Bruggink ED, Wobbes T, Strobbe LJ. Arm morbidity after complete axillary lymph node dissection for breast cancer. Acta Chir Belg. 2003;103:212-6.

5. Voogd AC, Ververs JM, Vingerhoets AJ, Roumen RM, Coebergh JW, Crommelin MA. Lymphoedema and reduced shoulder function as 
indicators of quality of life after axillary lymph node dissection for invasive breast cancer. Br J Surg. 2003;90:76-81, doi: 10.1002/bjs.4010.

6. Nesvold IL, Dahl AA, Lłkkevik E, Marit Mengshoel A, Fosså SD. Arm and shoulder morbidity in breast cancer patients after breast-conserving therapy versus mastectomy. Acta Oncol. 2008;47:835-42, doi: 10.1080/ 02841860801961257.

7. Swenson KK, Nissen MJ, Leach JW, Post-White J. Case-control study to evaluate predictors of lymphedema after breast cancer surgery. Oncol Nurs Forum. 2009;36:185-93, doi: 10.1188/09.ONF.185-193.

8. Sugden EM, Rezvani M, Harrison JM, Hughes LK. Shoulder movement after the treatment of early stage breast cancer. Clin Oncol (R Coll Radiol). 1998;10:173-81.

9. Tsai RJ, Dennis LK, Lynch CF, Snetselaar LG, Zamba GK, Scott-Conner C. The risk of developing arm lymphedema among breast cancer survivors: a meta-analysis of treatment factors. Ann Surg Oncol. 2009;16:1959-72, doi: 10.1245/s10434-009-0452-2.

10. Clark B, Sitzia J, Harlow W. Incidence and risk of arm oedema following treatment for breast cancer: a three-year follow-up study. QJM. 2005;98:343-8, doi: 10.1093/qjmed/hci053.

11. Ernst MF, Voogd AC, Balder W, Klinkenbijl JH, Roukema JA. Early and late morbidity associated with axillary levels I-III dissection in breast cancer. J Surg Oncol. 2002;79:151-5, doi: 10.1002/jso.10061.

12. Janni W, Rjosk D, Dimpfl TH, Haertl K, Strobl B, Hepp F, et al. Quality of life influenced by primary surgical treatment for stage I-III breast cancer-longterm follow-up of a matched-pair analysis. Ann Surg Oncol. 2001;8:542-8.

13. Waljee JF, Hu ES, Ubel PA, Smith DM, Newman LA, Alderman AK. Effect of esthetic outcome after breast-conserving surgery on psychosocial functioning and quality of life. J Clin Oncol. 2008;26:3331-7, doi: 10. 1200/JCO.2007.13.1375.

14. Roth RS, Lowery JC, Davis J, Wilkins EG. Quality of life and affective distress in women seeking immediate versus delayed breast reconstruction after mastectomy for breast cancer. Plast Reconstr Surg. 2005;15:9931002, doi: 10.1097/01.prs.0000178395.19992.ca.

15. Fung KW, Lau Y, Fielding R, Or A, Yip AW. The impact of mastectomy, breast-conserving treatment and immediate breast reconstruction on the quality of life of Chinese women. ANZ J Surg. 2001;71:202-6, doi: 10. 1046/j.1440-1622.2001.02094.x.

16. Engel J, Kerr J, Schlesinger-Raab A, Sauer H, Hölzel D. Quality of life following breast-conserving therapy or mastectomy: results of a 5-year prospective study. Breast J. 2004;10: 223-31, doi: 10.1111/j.1075-122X. 2004.21323.x

17. Härtl K, Janni W, Kästner R, Sommer H, Strobl B, Rack B, et al. Impact of medical and demographic factors on long-term quality of life and body image of breast cancer patients. Ann Oncol. 2003;14:1064-71, doi: 10. 1093/annonc/mdg289.

18. Ueda S, Tamaki Y, Yano K, Okishiro N, Yanagisawa T, Imasato M, et al. Cosmetic outcome and patient satisfaction after skin-sparing mastectomy for breast cancer with immediate reconstruction of the breast. Surgery. 2008;143:414-25, doi: 10.1016/j.surg.2007.10.006.

19. Dian D, Schwenn K, Mylonas I, Janni W, Friese K, Jaenicke F. Quality of life among breast cancer patients undergoing autologous breast reconstruction versus breast conserving therapy. J Cancer Res Clin Oncol. 2007;133:247-52, doi: 10.1007/s00432-006-0163-z.

20. Ware JE Jr., Sherbourne CD. The MOS 36-item short-form health survey (SF-36). I. Conceptual framework and item selection. Med Care. 1992;30:473-83, doi: 10.1097/00005650-199206000-00002.

21. Ciconelli RM, Ferraz MB, Santos W, Meinão I, Quaresma MR. BrazilianPortuguese version of the SF-36. A reliable and valid quality of life outcome measure. Rev Bras Reumatol. 1999;39:143-50.
22. Conde DM, Pinto-Neto AM, Cabello C, Santos-Sá D, Costa-Paiva L, Martinez EZ. Quality of life in Brazilian breast cancer survivors age 4565 years: associated factors. Breast J. 2005;11:425-32, doi: 10.1111/j.1075122X.2005.00124.x.

23. Parker PA, Youssef A, Walker S, Basen-Engquist K, Cohen L, Gritz ER, et al. Short-term and long-term psychosocial adjustment and quality of life in women undergoing different surgical procedures for breast cancer. Ann Surg Oncol. 2007;14:3078-89, doi: 10.1245/s10434-007-9413-9.

24. Ware JE Jr., Snow KK, Kosinski M, Gardek B. The SF-36 Health Survey Manual and Interpretation Guide. Boston, MA: Quality Metric Incorporated, 2000.

25. Armer J, Fu MR, Wainstock JM, Zagar E, Jacobs LK. Lymphedema following breast cancer treatment, including sentinel lymph node biopsy. Lymphology. 2004;37:73-91.

26. American Physical Therapy Association. Impaired circulation and anthropometric dimensions associated with lymphatic system disorders: evaluation, diagnosis, and prognosis. Guide to Physical Therapist Practice. 2nd ed. Alexandria, VA: American Physical Therapy Association, 2001.

27. Hosmer DW, Lemeshow S. Applied logistic regression. 2nd ed. New York: John Wiley and Sons, 2000.

28. Dielman TE. Least absolute value regression: recent contributions. JSCS 2005;75:263-86.

29. Elder EE, Brandberg Y, Björklund T, Rylander R, Lagergren J, Jurell G, et al. Quality of life and patient satisfaction in breast cancer patients after immediate breast reconstruction: a prospective study. Breast. 2005;14:201-8, doi: 10.1016/j.breast.2004.10.008.

30. Erickson VS, Pearson ML, Ganz PA, Adams J, Kahn KL. Arm edema in breast cancer patients. J Natl Cancer Inst. 2001;93:96-111, doi: 10.1093/ jnci/93.2.96.

31. Al-Ghazal SK, Fallowfield L, Blamey RW. Comparison of psychological aspects and patient satisfaction following breast conserving surgery, simple mastectomy and breast reconstruction. Eur J Cancer. 2000:36:1938-43, doi: 10.1016/S0959-8049(00)00197-0.

32. Nicholson RM, Leinster S, Sassoon EM. A comparison of the cosmetic and psychological outcome of breast reconstruction, breast conserving surgery and mastectomy without reconstruction. Breast. 2007;16:396-410, doi: 10.1016/j.breast.2007.01.009.

33. Kemeny MM, Wellisch DK, Schain WS. Psychosocial outcome in a randomized surgical trial for treatment of primary breast cancer. Cancer. 1988;62:1231-7, doi: 10.1002/1097-0142(19880915)62:6<1231::AIDCNCR2820620631>3.0.CO;2-8.

34. Lasry JC, Margolese RG, Poisson R, Shibata H, Fleischer D, Lafleur D, et al. Depression and body image following mastectomy and lumpectomy. J Chronic Dis. 1987:40:529-34, doi: 10.1016/0021-9681(87)90010-5.

35. de Haes JC, van Oostrom MA, Welvaart K. The effect of radical and conserving surgery on the quality of life of early breast cancer patients. Eur J Surg Oncol. 1986;12:337-42.

36. Ganz PA, Desmond KA, Leedham B, Rowland JH, Meyerowitz BE, Belin TR. Quality of life in long-term, disease-free survivors of breast cancer: a follow-up study. J Natl Cancer Inst. 2002;94:39-49.

37. Kenny P, King MT, Shiell A, Seymour J, Hall J, Langlands A, et al. Early stage breast cancer: costs and quality of life one year after treatment by mastectomy or conservative surgery and radiation therapy. Breast. 2000;9:37-44, doi: 10.1054/brst.1999.0111.

38. Lopes AD, Vilar e Furtado R, Silva CA, Yi LC, Malfatti CA, Araújo SA Comparison of self-report and interview administration methods based on the Brazilian versions of the Western Ontario Rotator Cuff Index and Disabilities of the Arm, Shoulder and Hand Questionnaire in patients with rotator cuff disorders. Clinics. 2009;64:121-5. 